\title{
Acid-Base and Electrolyte Status during Normovolemic Hemodilution with Succinylated Gelatin or HES- Containing Volume Replacement Solutions in Rats
}

\author{
Johanna K. Teloh ${ }^{1}$, Katja B. Ferenz ${ }^{1}$, Frank Petrat ${ }^{1}$, Christian Mayer ${ }^{2}$, Herbert de Groot ${ }^{1}{ }^{*}$ \\ 1 University of Duisburg-Essen, Institute of Physiological Chemistry, University Hospital Essen, Essen, Germany, 2 University of Duisburg-Essen, Institute of Physical \\ Chemistry, Essen, Germany
}

\begin{abstract}
Background: In the past, several studies have compared different colloidal replacement solutions, whereby the focus was usually on the respective colloid. We therefore systematically studied the influence of the carrier solution's composition of five approved colloidal volume replacement solutions (Gelafundin, Gelafusal, Geloplasma, Voluven and Volulyte) on acidbase as well as electrolyte status during and following acute severe normovolemic hemodilution. The solutions differed in the colloid used (succinylated gelatin vs. HES) and in the presence and concentration of metabolizable anions as well as in their electrolyte composition.

Methods: Anesthetized Wistar rats were subjected to a stepwise normovolemic hemodilution with one of the solutions until a final hematocrit of $10 \%$. Subsequent to dilution $(162 \mathrm{~min})$, animals were observed for an additional period (150 $\mathrm{min})$. During dilution and observation time blood gas analyses were performed eight times in total. Additionally, in the Voluven and Volulyte groups as well as in 6 Gelafundin animals, electrolyte concentrations, glucose, $\mathrm{pH}$ and succinylated gelatin were measured in urine and histopathological evaluation of the kidney was performed.

Results: All animals survived without any indications of injury. Although the employed solutions differed in their respective composition, comparable results in all plasma acid-base and electrolyte parameters studied were obtained. Plasma $\mathrm{pH}$ increased from approximately 7.28 to 7.39 , the plasma $\mathrm{K}^{+}$concentration decreased from circa $5.20 \mathrm{mM}$ to $4.80-3.90 \mathrm{mM}$ and the plasma $\mathrm{Cl}^{-}$concentration rose from approximately $105 \mathrm{mM}$ to $111-120 \mathrm{mM}$. Urinary analysis revealed increased excretion of $\mathrm{K}^{+}, \mathrm{H}^{+}$and $\mathrm{Cl}^{-}$.

Conclusions: The present data suggest that the carrier solution's composition with regard to metabolizable anions as well as $\mathrm{K}^{+}, \mathrm{Ca}^{2+}$ only has a minor impact on acid-base and electrolyte status after application of succinylated gelatin or HEScontaining colloidal volume replacement solutions.
\end{abstract}

Citation: Teloh JK, Ferenz KB, Petrat F, Mayer C, de Groot H (2013) Acid-Base and Electrolyte Status during Normovolemic Hemodilution with Succinylated Gelatin or HES-Containing Volume Replacement Solutions in Rats. PLoS ONE 8(9): e72848. doi:10.1371/journal.pone.0072848

Editor: Partha Mukhopadhyay, National Institutes of Health, United States of America

Received February 28, 2013; Accepted July 15, 2013; Published September 2, 2013

Copyright: (c) 2013 Teloh et al. This is an open-access article distributed under the terms of the Creative Commons Attribution License, which permits unrestricted use, distribution, and reproduction in any medium, provided the original author and source are credited.

Funding: The authors have no support or funding to report.

Competing Interests: The authors have declared that no competing interests exist.

*E-mail: herbert.de-groot@uni-duisburg-essen.de

\section{Introduction}

Colloids are often added to solutions that are applied for volume replacement to establish or maintain a colloid osmotic pressure in the intravascular compartment after infusion [1]. Colloidal solutions, as an alternative to crystalloid solutions, have been recommended in several resuscitation guidelines [2], although still controversially discussed [3,4]. Based on the affiliation of the colloid osmotic substances, a classification in natural (for example albumin) and synthetic colloids (i.e., dextran, hydroxyethyl starch (HES) or succinylated gelatin) can be made [1].

For production of succinylated gelatin (modified fluid gelatin), bovine collagen is thermically degraded before succinic anhydride is added, which reacts during the process of succinylation with the gelatin's basic amino groups [4,5]. Hence, those groups are finally substituted with carboxyl groups being deprotonated at physiological pH (Figure 1). The introduction of the negatively charged succinyl groups, which are repelled by the similarly charged endothelial glycocalyx, plus the conformational changes in the succinylated gelatin's molecular structure, result in an elevated intravascular dwell-time of solutions containing succinylated gelatin in comparison to unmodified gelatin.

HES is a highly branched starch polymer for which amylopectin serves as raw material [6]. The amylopectin's basic glucose units are linked via $\alpha-1,4$ glycosidic bonds [7]. Additional ramifications are realized via $\alpha-1,6$ glycosidic bonds. For application as a component in a medical product, the native starch polymer first has to be degraded into smaller fragments, either enzymatically or via acid hydrolysis. Due to several reasons (for example gelatinization and rapid degradation by endogenous $\alpha$-amylase), natural, unmodified starch cannot be employed as colloid osmotic active substance in a volume replacement solution [8]. Thus, the molecule experiences some modifications in order to enhance its 
1<smiles>CNC(=O)C(N)CCCCNC(=O)CCC(=O)[O-]</smiles>

2

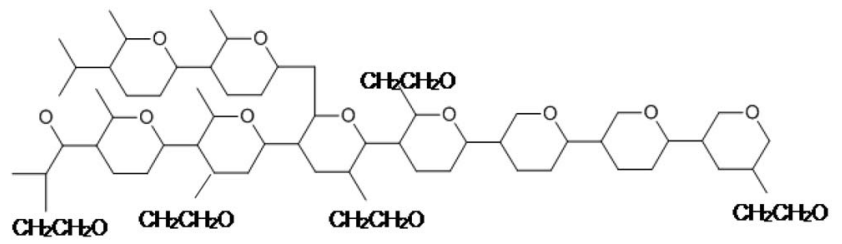

Figure 1. Chemical structure of the colloidal substances employed. 1) Succinylated gelatin chain whose terminal carboxyl group ist deprotonated at physiological $\mathrm{pH}$. 2) Hydroxyethyl starch whose single glucose subunits are additionally hydroxyethylated at carbon atoms two, three and six.

doi:10.1371/journal.pone.0072848.g001

properties in vivo. For this purpose, the starch molecule is hydroxyethylated at carbon atoms at the positions two, three and six within every glucose subunit, using amylopectin and ethylene oxide in an alkaline setting [9]. That way, water solubility is increased [8] and cleaveage by $\alpha$-amylase is delayed, but not completely prevented, resulting in a prolonged volume effect $[7,9]$. Nonetheless, HES molecules are enzymatically degraded until the fragments are small enough to pass the renal filtration barrier and are finally excreted. In contrast to succinylated gelatin, the starch polymer is neither deprotonated nor protonated at physiological $\mathrm{pH}$, thus being uncharged (Figure 1).

Colloid osmotic substances are dissolved in an aqueous solution, the so-called carrier solution. To ensure an unproblematic substitution, the current carrier solutions are approximately isoosmotic. They contain, however, the various electrolytes $\left(\mathrm{Na}^{+}\right.$, $\mathrm{K}^{+}, \mathrm{Ca}^{2+}$ and $\left.\mathrm{Cl}^{-}\right)$in different concentrations. Furthermore, some carrier solutions additionally include organic anions such as lactate and acetate. These so-called metabolizable anions are able to counteract acidosis due to the unavoidable dilution of bicarbonate upon application of the bicarbonate-free volume substitutes. Per anion metabolized, one $\mathrm{H}^{+}$is consumed and one $\mathrm{HCO}_{3}{ }^{-}$is generated. Thus, the physiological $\mathrm{pH}$ is considered to be especially preserved by those solutions containing a metabolizable anion [10] as long as sufficient oxygen is provided [11]. Solutions mimicking physiological concentrations of various ions in plasma, including metabolizable anions for bicarbonate substitution, are called balanced solutions, whereas pure saline-based carrier solutions containing rather unphysiological concentrations of $\mathrm{Na}^{+}$and $\mathrm{Cl}^{-}$are named unbalanced.

In the past, several studies have been performed of which many exhibited either a clinical background or were in vitro studies. This implicates that hemodilutions were rather moderate in the clinical setting $[12,13]$ or display the disadvantages of an in vitro situation [14,15] and are therefore not directly applicable. Those in total heterogeneous studies compared either crystalloid with colloidal volume replacement solutions $[16,17]$ or several colloidal replacement solutions containing different colloids in different clinical settings (for example HES vs. gelatin $[12,18]$, dextran vs. HES vs. albumin [13], albumin vs. gelatin vs. HES [19]) as regards mortality or the requirement of kidney transplantation but never the focus was solely on acid-base status. A few also analysed the influence of balanced or unbalanced carrier solutions but only with HES as colloid osmotic substance [20-23]. The carrier solution's impact in the presence of succinylated gelatin as identical colloid has never been analyzed to our knowledge.

To study the carrier solution's impact in the presence of succinylated gelatin as osmotically active substance on acid-base and electrolyte status, we employed three already approved solutions for volume replacement, i.e., Gelafundin, Gelafusal and Geloplasma, differing by the presence and concentration of electrolytes and metabolizable anions (Table 1) in a model of severe normovolemic hemodilution to a final hematocrit of $10 \%$. To examine the different influence of the colloid osmotic substance itself, we also included two approved HES solutions (i.e., Voluven and Volulyte). The model of severe normovolemic hemodilution was chosen to substitute a maximal amount of fluid and thus to enforce a marked change in the parameters studied without any influence of pathological mechanisms like centralizing of circulation or stop of aerobic glycolysis both present in hypovolemia and hemorrhagic shock.

\section{Methods}

\section{Ethics Statement}

Experiments were conducted in accordance with the standards of Annex III of the directive 2010/63/EU of the European Parliament and of the Council of 22 September 2010 on the protection of animals used for scientific purposes [24]. The experimental protocol was reviewed and approved by the local Animal Care and Use Committee (Animal Care Cienter, University of Duisburg-Essen, Essen, Germany, and the district government of Duesseldorf ("North Rhine-Westphalia State Environment Agency", Recklinghausen, Germany), Germany) with a Permit Number 84-02.04.2012.A327, G1314/12) All surgery was performed under isoflurane anesthesia, and all efforts were made to minimize suffering.

\section{Animals}

A total number of 36 male Wistar rats (Rattus norvegicus, $410 \mathrm{~g}$ $470 \mathrm{~g}$ ) were obtained from the central animal unit of the Essen University Hospital. Animals were kept under standardized conditions of temperature $\left(22^{\circ} \mathrm{C} \pm 1{ }^{\circ} \mathrm{C}\right)$, humidity $(55 \% \pm 5 \%)$, and 12- h/12- h light dark cycles. They were fed ad libitum (SsniffSpezialdiaeten, Soest, Germany) with free access to water and not fasted before the experiments.

\section{Chemicals/Materials}

Gelafundin and $\mathrm{NaCl}$ solution $(0.9 \%)$ was provided by B. Braun (Melsungen, Germany), Gelafusal by Serumwerk Bernburg (Bernburg, Germany) and Geloplasma, Voluven and Volulyte by Fresenius Kabi (Bad Homburg, Germany). Isoflurane (Forene) was obtained from Abbott (Wiesbaden, Germany), ketamine 10\% from Geva (Duesseldorf, Germany) and lidocaine (Xylocain 1\%) from AstraZeneca (Wedel, Germany). Portex catheters (0.58 mm inner diameter, $0.96 \mathrm{~mm}$ outer diameter) were from Smiths Medical International (Hythe, UK). As urinary catheter an indwelling venous cannula was used (Vasofix, B. Braun, Melsungen, Germany). For dilution of urine, a special diluent was employed (Radiometer, Copenhagen, Denmark). Medical oxygen was from Air Liquide (Duesseldorf, Germany). 
Table 1. Composition of the five volume replacement solutions Gelafundin, Gelafusal, Geloplasma, Voluven and Volulyte.

\begin{tabular}{|c|c|c|c|c|c|}
\hline & Gelafundin & Gelafusal & Geloplasma & Voluven & Volulyte \\
\hline $\begin{array}{l}\text { colloid osmotic } \\
\text { active substance }\end{array}$ & $\begin{array}{l}\text { Succinylated } \\
\text { gelatin }\end{array}$ & $\begin{array}{l}\text { Succinylated } \\
\text { gelatin }\end{array}$ & $\begin{array}{l}\text { Succinylated } \\
\text { gelatin }\end{array}$ & $\begin{array}{l}\text { Hydroxyethyl } \\
\text { starch }\end{array}$ & $\begin{array}{l}\text { Hydroxyethyl } \\
\text { starch }\end{array}$ \\
\hline quantity [g/L] & 40 & 40 & 30 & 60 & 60 \\
\hline \multirow{2}{*}{$\begin{array}{l}\text { real osmolality } \\
\text { [mOsm } / \mathrm{kg}]\end{array}$} & 265 & 270 & 273 & 304 & 283 \\
\hline & molarity $[\mathrm{mM}]$ & & & & \\
\hline $\mathrm{Na}^{+}$ & 154 & 130 & 150 & 154 & 137 \\
\hline $\mathbf{K}^{+}$ & - & 5.4 & 5 & - & 4.0 \\
\hline $\mathrm{Ca}^{2+}$ & - & 0.9 & - & - & - \\
\hline $\mathbf{M g}^{2+}$ & - & 1.0 & 1.5 & - & 1.5 \\
\hline $\mathrm{Cl}^{-}$ & 120 & 85 & 100 & 154 & 110 \\
\hline lactate & - & - & 30 & - & - \\
\hline acetate & - & 27 & - & - & 34 \\
\hline
\end{tabular}

Note: The apparent anion gap in the case of Gelafundin, Gelafusal and Geloplasma is compensated by the negative charge of succinylated gelatin. doi:10.1371/journal.pone.0072848.t001

\section{Anesthesia, Analgesia, and Surgical Procedures}

Rats were anesthetized with isoflurane $(2.0 \%$ in $100 \%$ medical $\mathrm{O}_{2}$ at $4.0 \mathrm{l} / \mathrm{min}$ for induction, $1.0 \%-2.0 \%$ isoflurane in $100 \%$ medical $\mathrm{O}_{2}$ at $1.0 \mathrm{l} / \mathrm{min}$ throughout the experiment) through face masks connected to a vaporizer (Isofluran Vet. Med. Vapor; Draeger, Luebeck, Germany) and received ketamine $(50 \mathrm{mg} / \mathrm{kg}$ body weight subcutaneously) into the right chest wall for analgesia. After local lidocaine administration $(5 \mathrm{mg} / \mathrm{kg}$ body weight subcutaneously), a skin-deep inguinal incision of about $2 \mathrm{~cm}$ was made, and a Portex catheter $(0.58 \mathrm{~mm}$ inner diameter, $0.96 \mathrm{~mm}$ outer diameter) was placed within the right femoral artery and the right femoral vein. For insertion of the urinary catheter, a median inguinal incision of about $2 \mathrm{~cm}$ was made with subsequent preparation of the urinary bladder. For the period of infusion of the volume replacement solution, the prolonged infusion of $0.9 \%$ $\mathrm{NaCl}$-solution $\left(5 \mathrm{ml} / \mathrm{kg}\right.$ body weight $\mathrm{x} \mathrm{h}, 37^{\circ} \mathrm{C}$ ) to compensate intraoperative fluid depletion over surgical areas and the respiratory epithelium was interrupted. At the end of the experiment, the left kidney from animals of the Voluven and Volulyte group as well as from 6 animals of the Gelafundin group (see experimental groups) was harvested. All animals were sacrificed by resection of the heart under deep isoflurane anesthesia.

\section{Hemodilution}

The model of normovolemic hemodilution was established according to Johannes and Young $[25,26]$, with some modifications.

Briefly, $3 \mathrm{ml}$ blood was repetitively withdrawn until a final hematocrit of $10 \% \pm 1 \%$ was attained. Every withdrawal was followed by a 15- min pause interval for circulatory stabilization as established previously [25,26]. The blood was taken from the arterial catheter at an approximate rate of $1 \mathrm{ml} / \mathrm{min}$ by hand [26]. The removed volume was simultaneously replaced over the venous catheter $(1 \mathrm{ml} / \mathrm{min})$ by one of the five volume replacement solutions using a syringe pump (Medfusion Inc, Raleigh, United States). After finishing hemodilution, animals were monitored for 150 min. If mean arterial blood pressure (MAP) had fallen below $60 \mathrm{mmHg}$, a bolus of $0.5 \mathrm{ml}$ of the respective volume replacement solutions was given.
Hematocrit was measured with the help of a centrifuge (10 min, 22024.6 x g, $4^{\circ} \mathrm{C}$; Universal 320R, Hettich, Tuttlingen, Germany). For this purpose, blood samples $(0.3 \mathrm{ml})$ were taken from the femoral artery immediately before starting the next dilutional step using a 2- ml syringe (Pico50, Radiometer Medical ApS, Brønshøj, Denmark) containing 80 IU electrolyte-balanced heparin.

\section{Experimental Groups}

One group $(n=6)$ received Gelafusal for volume replacement during hemodilution, the second group $(n=6)$ Geloplasma, the third $(n=6)$ Voluven, the fourth $(n=6)$ Volulyte and the fifth $(n=12)$ Gelafundin. Parameters of the five groups were compared.

All animals of the Voluven and Volulyte group as well as 6 animals of the Gelafundin group experienced the insertion of a urinary catheter for continous urine collection and further analysis ( $\mathrm{pH}$, electrolytes as well as succinate analysis).

\section{Biomonitoring}

For close documentation of the established model, we monitored several systemic and vital parameters throughout the experiment. Systolic blood pressure, diastolic blood pressure and MAP were measured continuously by using the femoral artery catheter, which was connected to a pressure transducer, and displayed on a monitor. Ringer solution was infused at a rate of $3 \mathrm{ml} / \mathrm{h}$ to keep the catheter functional. Heart rates were determined from systolic blood pressure spikes. The breathing rate was determined according to the number of ventilatory movements in 15 seconds. The core body temperature of all rats was monitored using a rectal sensor and maintained around $37.3^{\circ} \mathrm{C}$ during the whole experiment by means of an underlying thermostat-controlled operating table and by covering the animal additionally with aluminum foil.

\section{Assessment of Blood Parameters}

Using a 2- ml syringe containing 80 IU electrolyte-balanced heparin, blood samples $(2 \mathrm{ml})$ were taken from the femoral artery (as part of the blood withdrawn for hemodilution) at the first, fourth, seventh and ninth dilutional step as well as $0.3 \mathrm{ml}$ each at 15, 45, 90 and $150 \mathrm{~min}$ after dilution had been completed. 
Arterial oxygen and carbon dioxide partial pressure $\left(\mathrm{pO}_{2}, \mathrm{pCO}_{2}\right)$, $\mathrm{pH}$, base excess, electrolytes $\left(\mathrm{Na}^{+}, \mathrm{K}^{+}, \mathrm{Ca}^{2+}\right.$ and $\left.\mathrm{Cl}^{-}\right)$and metabolic parameters (lactate, glucose) were assessed with a blood gas analyzer (ABL 715, Radiometer, Copenhagen, Denmark).

\section{Assessment of Urinary Parameters}

After insertion of the urinary catheter, the initial urine was removed and stored at $-80^{\circ} \mathrm{G}$ until further examination. Both during the phase of dilution and during the observation time, urine was continuosly collected and again stored at $-80^{\circ} \mathrm{C}$. $\mathrm{Na}^{+}, \mathrm{K}^{+}$, $\mathrm{Ca}^{2+}, \mathrm{Cl}^{-}$and glucose were analyzed with the help of a blood gas analyzer (ABL 715, Radiometer, Copenhagen, Denmark). Prior to these measurements, urine samples were diluted 1:2 with urine diluent. To verify results obtained by the blood gas analyzer as regards the glucose amount in urine, we employed urine testing strips, confirming this data. The $\mathrm{pH}$ was measured with the help of an electrode.

All urine samples were submitted to quantitative analysis of succinylated gelatin by nuclear magnetic resonance (NMR). Without further sample preparation, ${ }^{1} \mathrm{H}$ line spectra were measured using $5 \mathrm{~mm}$ sample tubes in a DRX 500 spectrometer (Bruker, Karlsruhe, Germany) by accumulation of 320 scans. An external reference of $\mathrm{D}_{2} \mathrm{O}$ (with traces of HDO) in a coaxial tube was used to create the lock signal. The free induction decay induced by a single 90 degree pulse for protons was accumulated and subsequently Fourier-transformed to generate a corresponding line spectrum. A waiting period of 7 seconds between the scans allowed for sufficient spin-lattice relaxation. The spectra were referenced to the proton signal of HDO to $4.8 \mathrm{ppm}$.

Using a corresponding spectrum of a commercial succinylated gelatin-containing solution (4\%, Gelafundin), the signals at $2.394 \mathrm{ppm}$ and at $2.433 \mathrm{ppm}$ could be identified as deriving from the two different $\mathrm{CH}_{2}$-segments of the succinate residue connected to the gelatin chain. Both together, they served as markers for the presence of succinylated gelatin. The assignment of these peaks has been confirmed by ${ }^{1} \mathrm{H}-{ }^{13} \mathrm{C}$-correlation spectroscopy and by comparison with the proton spectrum of sodium succinate solution. In the urine samples, only a single peak near $2.39 \mathrm{ppm}$ could be detected, indicating that only free succinate (with two equivalent $\mathrm{CH}_{2}$-groups) was present. For a quantitative analysis, this section of the proton spectra was integrated and referenced to the combined signal intensities $\left(\mathrm{I}_{\mathrm{G}}=\mathrm{I}_{2.394 \mathrm{ppm}}+\mathrm{I}_{2.433 \mathrm{ppm}}\right)$ of Gelafundin with a succinylated gelatin concentration of $\mathrm{c}_{\mathrm{G}}=4 \%$. The succinate concentration for a given sample $\mathrm{x}$ was then calculated as $\mathrm{c}_{\mathrm{x}}=\mathrm{c}_{\mathrm{G}}\left(\mathrm{I}_{\mathrm{x}} / \mathrm{I}_{\mathrm{G}}\right)$. Considering the possible presence of weak background signals and baseline distortions, an experimental uncertainty of $\pm 10 \%$ was accepted.

Both the initial urine of the Gelafundin group as well as the one of Voluven group collected during observation time were estimated on the basis of 3 animals. Other mean values were calculated on the basis of 6 animals.

\section{Histopathologic Evaluation of the Kidney}

The entire left kidney was fixed for $24 \mathrm{~h}$ to $48 \mathrm{~h}$ in formalin (10\% neutral buffered). Paraffin-embedded sections $(3 \mu \mathrm{m})$ were made and subsequently stained with hematoxylin-eosin and evaluated.

\section{Statistical Analysis}

Experiments were performed with 6 animals per group (Gelafundin group: 12 animals). The data are expressed as mean values \pm standard error of the mean (SEM). Comparisons among different time points within one group or among multiple groups at one time point were performed using one-way independent analysis of variance (ANOVA), whereas comparisons for an analysis over time were performed using repeated measurements ANOVA, both followed by the Fisher (LSD) post hoc analysis. A $P$ value $<0.05$ was considered significant.

\section{Results}

\section{Hematocrit, Blood Pressure and other Vital Parameters}

In the course of hemodilution, the hematocrit dropped steadily in the animals substituted with colloidal replacement solutions containing either succinylated gelatin (Figure 2) or solutions on HES basis (data not shown). Between the single groups no differences were detectable. The final hematocrit of $10 \% \pm 1 \%$ was reached after nine steps of dilution (162 min) in all groups. All animals survived the whole experimental time of hemodilution and the subsequent observation time $(150 \mathrm{~min})$. The MAP of all animals having received succinylated gelatin slightly decreased during the experiment, both during the phase of dilution and the observation time, but never fell below $70 \mathrm{mmHg}$ (Figure 3). The same was true for the Voluven and Volulyte groups (data not shown). The heart and breathing rate remained constant over the experiment in all groups studied (data not shown).

\section{Acid-base and Metabolic Status}

In all groups, the plasma $\mathrm{pH}$ rose throughout the experiment (Figure 4), and there was no significant difference between the groups. The $\mathrm{pH}$ increased from values around 7.28 to 7.34 (Gelafundin), 7.38 (Volulyte), 7.40 (Voluven), 7.41 (Gelafusal) and 7.42 (Geloplasma), respectively, shortly after hemodilution had been completed. During the subsequent observation time, the $\mathrm{pH}$ of these groups stayed approximately constant to end up at a final value of 7.39 (Gelafundin and Gelafusal), 7.40 (Geloplasma and Volulyte) and 7.43 (Voluven), respectively.

Again in all groups, $\mathrm{pCO}_{2}$ decreased from initial values of 55 to $60 \mathrm{mmHg}$ to values of 35 to $45 \mathrm{mmHg}$ (Figure 4). During the observation time it dropped even further to values of 30 to $37 \mathrm{mmHg}$ which were kept until the end of the experiment.

Throughout the experiment the $\mathrm{pO}_{2}$ remained almost constant around $400 \mathrm{mmHg}$ in all animals (data not shown).

Starting from values around-1 to $0 \mathrm{mM}$, base excess slightly increased during hemodilution in the Gelafusal, Geloplasma and Volulyte groups or stayed constant (Gelafundin), but decreased a little in the Voluven group to-3 $\mathrm{mM}$ (Figure 4). Upon cessation of

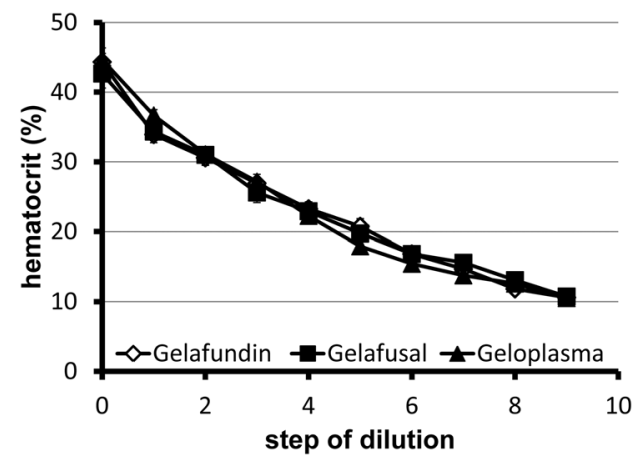

Figure 2. Effect of hemodilution on the current hematocrit. Rats underwent uniform normovolemic hemodilution to a final hematocrit of $10 \%$ with either Gelafundin, Gelafusal or Geloplasma by withdrawal of $3 \mathrm{ml}$ blood per step. An interval of $15 \mathrm{~min}$ was left between the single steps. Hematocrit was determined in arterial blood samples immediately before the next withdrawal. doi:10.1371/journal.pone.0072848.g002 


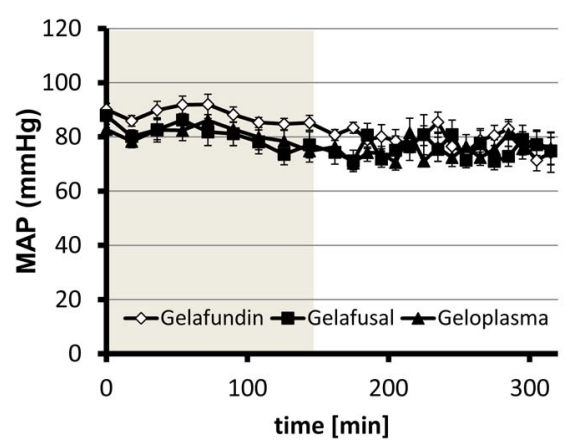

Figure 3. Influence of different volume replacement solutions on blood pressure during and subsequent to normovolemic hemodilution. Rats underwent normovolemic hemodilution to a final hematocrit of $10 \%$ for 162 min (phase of hemodilution: light grey) with either Gelafundin, Gelafusal or Geloplasma and were subsequently observed for $150 \mathrm{~min}$. For analysis mean arterial blood pressure was monitored.

doi:10.1371/journal.pone.0072848.g003 dilution, base excess dropped to-2 $\mathrm{mM}$ (Gelafusal, Geloplasma, Volulyte),-3 mM (Gelafundin) and-5 $\mathrm{mM}$ (Voluven), respectively, to stay at the respective level during the whole observation time.

The blood lactate concentration remained at levels below $1.9 \mathrm{mM}$ in the Gelafundin, Gelafusal, Voluven and Volulyte groups, both during the phase of dilution and during the observation time, with the tendency to decrease towards the end of the experiment (Table 2). In contrast, over the same period of time, the lactate concentration in the Geloplasma group increased to $2.7 \mathrm{mM}$. The blood glucose concentration of all groups remained in the range between 175 to $225 \mathrm{mg} / \mathrm{dl}$ during the phase of dilution. During the observation time, the glucose concentration steadily decreased to end up at values of $146 \mathrm{mg} / \mathrm{dl}$ (Voluven), $133 \mathrm{mg} / \mathrm{dl}$ (Volulyte), $131 \mathrm{mg} / \mathrm{dl}$ (Gelafundin), $115 \mathrm{mg} / \mathrm{dl}$ (Gelafusal) and $112 \mathrm{mg} / \mathrm{dl}$ (Geloplasma), respectively.

\section{Electrolytes}

The plasma concentration of $\mathrm{K}^{+}$steadily decreased throughout the experiment in all 5 groups from an initial value of
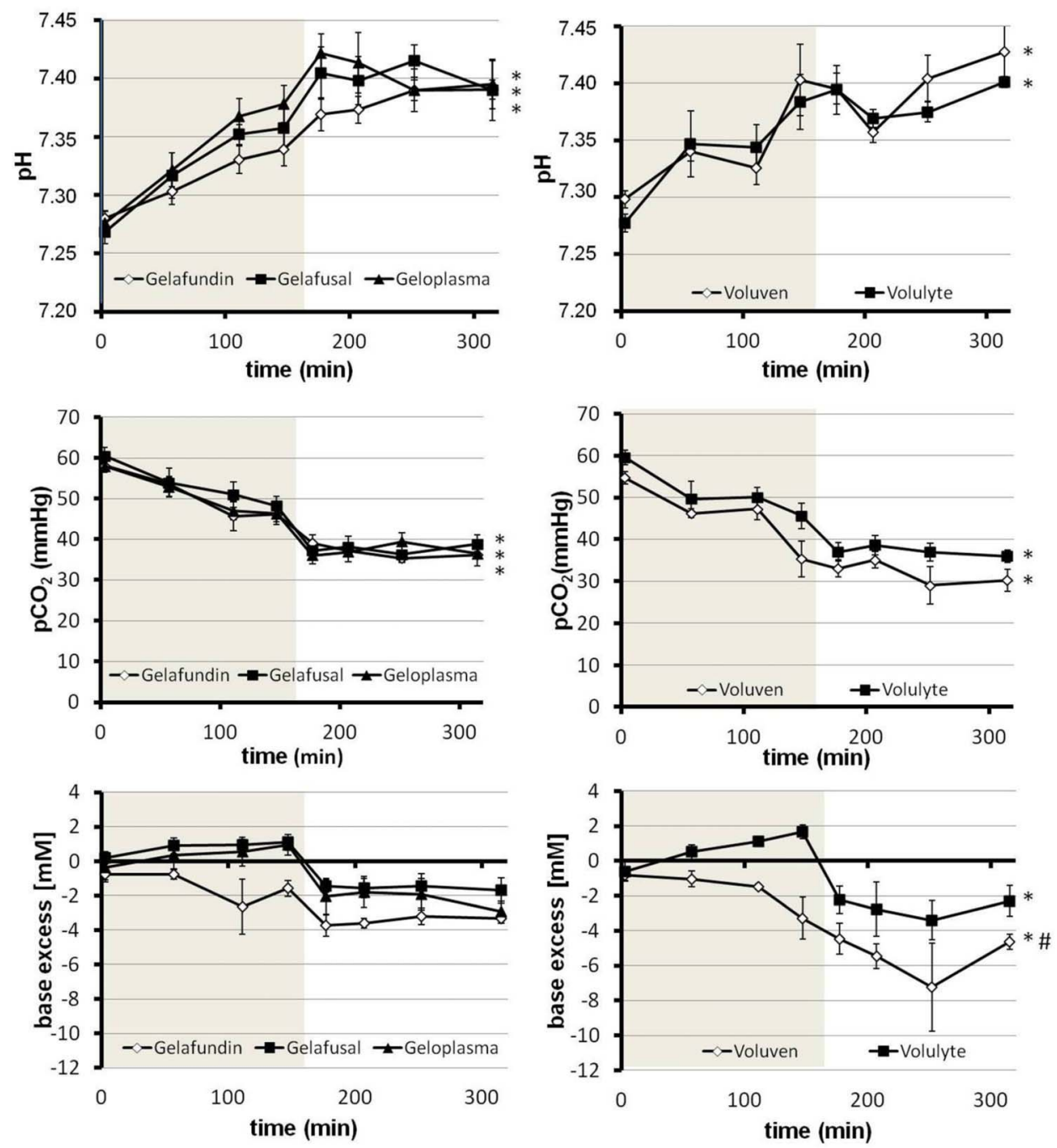

Figure 4. Impact of different volume replacement solutions on acid-base parameters during and subsequent to normovolemic hemodilution. Rats underwent normovolemic hemodilution to a final hematocrit of $10 \%$ for $162 \mathrm{~min}$ (phase of hemodilution: light grey) with either Gelafundin, Gelafusal, Geloplasma, Voluven or Volulyte and were subsequently observed for 150 min. Parameters were determined in arterial blood samples at the points indicated. * $<0.05$ compared with the value measured at $3 \mathrm{~min}$, in the respective group. \# $<0.05$ (Voluven vs. Volulyte). doi:10.1371/journal.pone.0072848.g004 
Table 2. Influence of different volume replacement solutions (Gelafundin, Gelafusal, Geloplasma, Voluven, Volulyte) on lactate and glucose in arterial blood samples during and subsequent to normovolemic hemodilution in rats.

\begin{tabular}{|c|c|c|c|c|c|c|c|c|c|c|}
\hline \multirow[b]{2}{*}{$\begin{array}{l}\text { time } \\
(\min )\end{array}$} & \multicolumn{2}{|c|}{ Gelafundin } & \multicolumn{2}{|c|}{ Gelafusal } & \multicolumn{2}{|c|}{ Geloplasma } & \multicolumn{2}{|c|}{ Voluven } & \multicolumn{2}{|c|}{ Volulyte } \\
\hline & $\begin{array}{l}\text { lactate } \\
\text { [mM] }\end{array}$ & $\begin{array}{l}\text { glucose } \\
\text { [mg/dl] }\end{array}$ & $\begin{array}{l}\text { lactate } \\
\text { [mM] }\end{array}$ & $\begin{array}{l}\text { glucose } \\
\text { [mg/dll] }\end{array}$ & $\begin{array}{l}\text { lactate } \\
\text { [mM] }\end{array}$ & $\begin{array}{l}\text { glucose } \\
\text { [mg/dll] }\end{array}$ & $\begin{array}{l}\text { lactate } \\
\text { [mM] }\end{array}$ & $\begin{array}{l}\text { glucose } \\
\text { [mg/dl] }\end{array}$ & $\begin{array}{l}\text { lactate } \\
\text { [mM] }\end{array}$ & $\begin{array}{l}\text { glucose } \\
\text { [mg/dl] }\end{array}$ \\
\hline 3 & $1.4 \pm 0.1$ & $193.7 \pm 3.6$ & $1.4 \pm 0.1$ & $195.2 \pm 9.3$ & $1.8 \pm 0.1$ & 212. $0 \pm 14.3$ & $1.3 \pm 0.1$ & $218.5 \pm 7.4$ & $1.3 \pm 0.1$ & $218.8 \pm 12.4$ \\
\hline 57 & $1.4 \pm 0.1$ & $190.8 \pm 3.5$ & $1.3 \pm 0.1$ & $186.3 \pm 6.1$ & $1.62 \pm 0.1$ & $199.2 \pm 9.4$ & $1.6 \pm 0.4$ & $205.7 \pm 10.7$ & $1.3 \pm 0.1$ & $213.0 \pm 19.3$ \\
\hline 111 & $1.4 \pm 0.1$ & $193.3 \pm 8.0$ & $1.4 \pm 0.1$ & $183.7 \pm 7.6$ & $1.9 \pm 0.1$ & $198.8 \pm 12.6$ & $1.5 \pm 0.2$ & $223.7 \pm 11.5$ & $1.3 \pm 0.2$ & $216.3 \pm 11.8$ \\
\hline 147 & $1.4 \pm 0.1$ & $191.8 \pm 9.8$ & $1.6 \pm 0.1$ & $179.8 \pm 5.1$ & $2.2 \pm 0.2$ & $212.7 \pm 16.1$ & $1.7 \pm 0.2$ & $204.5 \pm 11.2$ & $1.6 \pm 0.2$ & $217.7 \pm 16.6$ \\
\hline 177 & $1.3 \pm 0.1$ & $161.7 \pm 5.4$ & $1.5 \pm 0.2$ & $162.8 \pm 7.4$ & $2.1 \pm 0.4$ & $169.8 \pm 10.6$ & $1.7 \pm 0.2$ & $189.3 \pm 14.0$ & $1.8 \pm 0.2$ & $187.5 \pm 15.2$ \\
\hline 207 & $1.2 \pm 0.1$ & $145.8 \pm 6.3$ & $1.4 \pm 0.1$ & $151.2 \pm 2.1$ & $2.7 \pm 0.4$ & $147.8 \pm 9.9$ & $1.7 \pm 0.3$ & $197.2 \pm 14.3$ & $1.7 \pm 0.1$ & $188.5 \pm 19.6$ \\
\hline 252 & $1.0 \pm 0.0$ & $133.7 \pm 7.8$ & $1.1 \pm 0.1$ & $133.3 \pm 9.4$ & $1.6 \pm 0.3$ & $123.2 \pm 11.9$ & $1.2 \pm 0.2$ & $160.0 \pm 26.6$ & $1.2 \pm 0.2$ & $154.7 \pm 13.9$ \\
\hline 315 & $1.0 \pm 0.1$ & $126.7 \pm 6.6$ & $1.1 \pm 0.1$ & $115.0 \pm 9.2$ & $2.6 \pm 0.5$ & $112.0 \pm 12.8$ & $1.1 \pm 0.1$ & $146.0 \pm 26.6$ & $1.6 \pm 0.3$ & $133.2 \pm 16.0$ \\
\hline
\end{tabular}

doi:10.1371/journal.pone.0072848.t002

approximately $5.3 \mathrm{mM}$ to $4.8 \mathrm{mM}$ (Volulyte), $4.4 \mathrm{mM}$ (Gelafundin, Geloplasma), $4.3 \mathrm{mM}$ (Gelafusal) and $3.9 \mathrm{mM}$ (Voluven), respectively (Figure 5).

The $\mathrm{Na}^{+}$concentration in the Gelafundin, Geloplasma, Voluven and Volulyte groups steadily rose after beginning of hemodilution from initial values around $138 \mathrm{mM}$ to reach final values of $141 \mathrm{mM}$ (Voluven, Volulyte), $142 \mathrm{mM}$ (Gelafundin) and $143 \mathrm{mM}$ (Geloplasma) at the end of the experiment (Figure 5). The $\mathrm{Na}^{+}$concentration in the Gelafusal group stayed around $138 \mathrm{mM}$ during the whole experimental time.

For the phase of dilution, the plasma $\mathrm{Ca}^{2+}$ concentration remained between $1.34 \mathrm{mM}$ and $1.41 \mathrm{mM}$ in all groups studied (Figure 5). After cessation of hemodilution, there was an increase to values around $1.45 \mathrm{mM}$ in those groups diluted with Gelafundin, Gelafusal and Geloplasma, respectively. In the Voluven and Volulyte groups, $\mathrm{Ca}^{2+}$ concentration remained constant in this phase.

Starting from an initial value of approximately $105 \mathrm{mM}$, the plasma $\mathrm{Cl}^{-}$concentration stayed constant (Gelafusal and Geloplasma) or slightly increased (Gelafundin, Voluven and Volulyte) during the phase of dilution (Figure 5). In the subsequent observation time, the values rapidly increased reaching final values of $111 \mathrm{mM}$ (Gelafusal), $113 \mathrm{mM}$ (Geloplasma), $116 \mathrm{mM}$ (Gelafundin and Volulyte) and $120 \mathrm{mM}$ (Voluven), respectively.

\section{Electrolytes, Glucose and Succinylated Gelatin in Urine and Kidney Injury}

Urinary electrolytes, glucose, and succinylated gelatin as well as kidney injury were only studied in the Voluven and Volulyte group as well as in 6 animals of the Gelafundin group.

Animals of the Gelafundin and Volulyte groups excreted an urine volume of approximately $2 \mathrm{ml}$ both during the phase of dilution as well as during the observation time (Table 3). In contrast, in the Voluven group, urine excreted amounted to about double that volume, i.e., $5 \mathrm{ml}$ and $3 \mathrm{ml}$, respectively.

In all groups studied, during the phase of hemodilution, the urinary $\mathrm{pH}$ decreased from neutral to acidic values of 6.2 to 6.4 , remaining close to these values during the observation time (Table 3).

As compared to the initial values of around 60 to $90 \mathrm{mM}$, the $\mathrm{K}^{+}$concentration roughly doubled in the urine collected during hemodilution and was only somewhat further increased in the urine collected during the observation time (Table 3). Taken the urine volume of the respective interval into consideration, the total amount of $\mathrm{K}^{+}$excreted was the highest in the Voluven group (about $500 \mu \mathrm{mol}$, as compared to Volulyte $265 \mu \mathrm{mol}$, Gelafundin $380 \mu \mathrm{mol})$; with little differences in the amount excreted between the phase of dilution and the observation time.

There were only little changes in the urinary $\mathrm{Na}^{+}$concentration in the Gelafundin and Volulyte groups (Table 3). Only in the Voluven group, the urinary $\mathrm{Na}^{+}$concentration was increased from an initial value of ca. $50 \mathrm{mM}$ to values of ca. $100 \mathrm{mM}$, both in the urine collected during the phase of dilution and in the observation time. The absolute amounts of $\mathrm{Na}^{+}$excreted were about $100 \mu \mathrm{mol}$ for Gelafundin, $200 \mu \mathrm{mol}$ for Volulyte and $450 \mu \mathrm{mol}$ for Voluven. As with $\mathrm{K}^{+}$, differences between intervals were small.

In urine collected during the phase of dilution, only animals having received Voluven displayed an altered $\mathrm{Cl}^{-}$concentration which was two to three times as high as in the initial sample (50 to $85 \mathrm{mM}$, Table 3). In the samples collected during the observation time, $\mathrm{Cl}^{-}$concentration stayed approximately the same in the Voluven and Volulyte group and the Gelafundin group's value doubled. The absolut amount of $\mathrm{Cl}^{-}$excreted in the first interval was $200 \mu \mathrm{mol}$ (Volulyte and Gelafundin) and $800 \mu \mathrm{mol}$ (Voluven), respectively, whereas in the last interval, values doubled in the Volulyte and Gelafundin groups but the amount of $\mathrm{Cl}^{-}$excreted stayed nearly the same in the Voluven group.

During the phase of dilution, urinary glucose concentration increased about 40-fold in the Voluven and Volulyte group and 5fold in the Gelafundin group as compared to the initial concentration of $10 \mathrm{mg} / \mathrm{dl}$ (Table 3). In the observation time, these values stayed constant. Considering urine volume, $10 \mathrm{mg}$ glucose were excreted in the Voluven and Volulyte group and $1 \mathrm{mg}$ in the Gelafundin group in each interval.

NMR studies of the Gelafundin animals' urine showed traces of succinylated gelatin $(4.3 \mathrm{mg} / \mathrm{ml}$, absolute amount $3.9 \mathrm{mg})$ in the initial urine sample (Table 4). During the phase of dilution, animals' urine contained an average concentration of succinylated gelatin of $134.3 \mathrm{mg} / \mathrm{ml}$, which adds up to an amount of $301.8 \mathrm{mg}$. The concentration inn urine collected during the time of dilution was $88.6 \mathrm{mg} / \mathrm{ml}$ on average which corresponds to an excreted amount of $165.3 \mathrm{mg}$. Animals having been substituted with Voluven hardly excreted any succinylated gelatin in the observation time $(0.9 \mathrm{mg} / \mathrm{ml}$, absolute amount $1.5 \mathrm{mg})$.

Histological evaluation of the kidneys displayed vacoulization of proximal tubular cells in all groups studied (data not shown). Kidneys of the Gelafundin group tended to be more affected than 

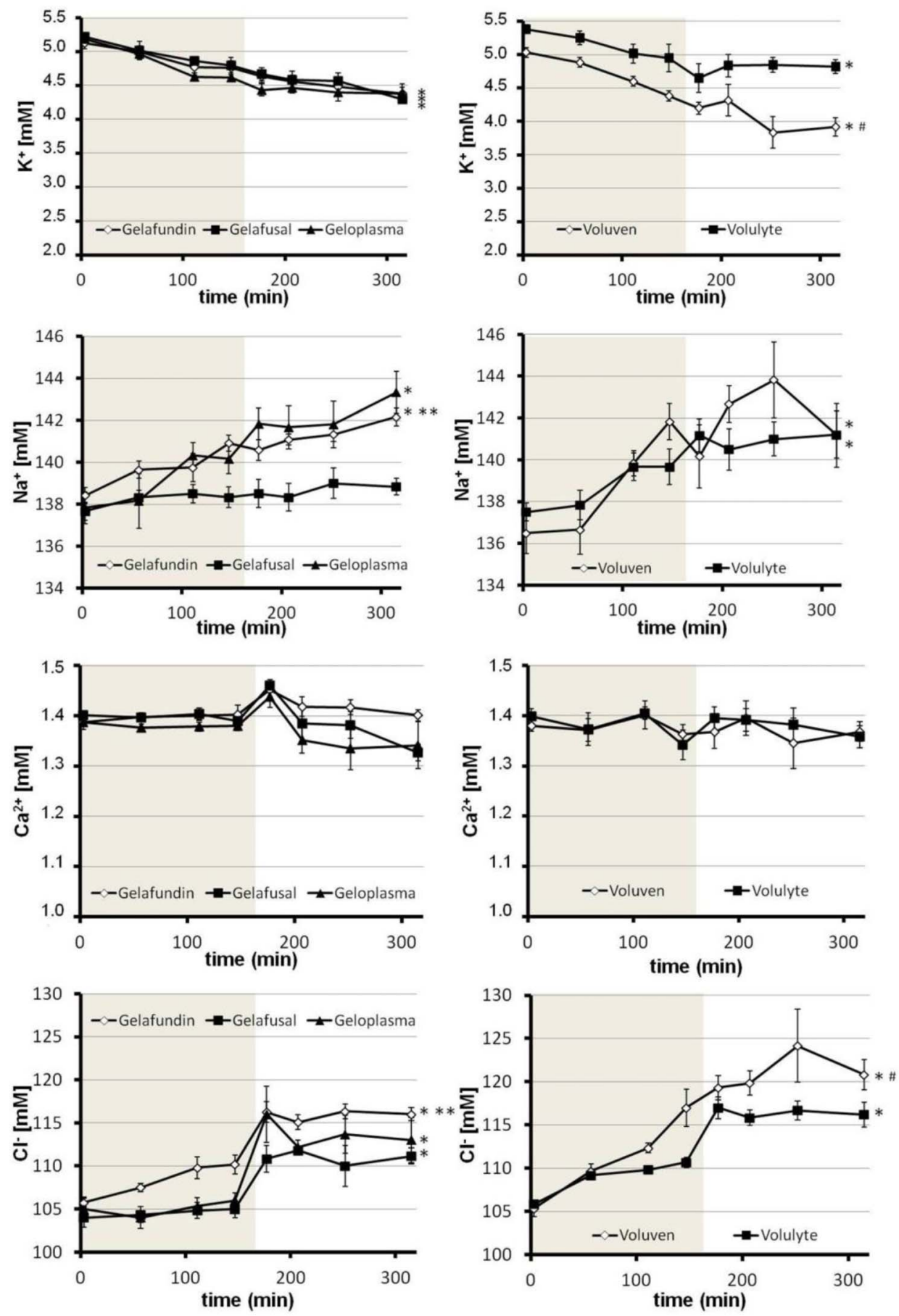

Figure 5. Effects of different volume replacement solutions on electrolyte parameters during and subsequent to normovolemic hemodilution. Rats underwent normovolemic hemodilution to a final hematocrit of $10 \%$ for 162 min (phase of hemodilution: light grey) with either Gelafundin, Gelafusal, Geloplasma, Voluven or Volulyte and were subsequently observed for $150 \mathrm{~min}$. Electrolytes were determined in arterial blood samples at the points indicated. * $<0.05$ compared with the value measured at $3 \mathrm{~min}$, in the respective group. \# $<0.05$ (Voluven vs. Volulyte) ${ }^{* *}$ $<0.05$ (Gelafundin vs. Gelafusal).

doi:10.1371/journal.pone.0072848.g005

those of the HES groups (Voluven and Volulyte). No differences were visible between the Voluven and Volulyte group.

\section{Discussion}

The three volume replacement solutions employed in this study on the basis of succinylated gelatin as colloid osmotic substance differ with regard to electrolytes and metabolizable anions (Table 1). Gelafusal as well as Geloplasma contain a metabolizable anion, acetate $(27 \mathrm{mM})$ and lactate $(30 \mathrm{mM})$, respectively, whereas Gelafundin does not. Apart from the presence of an organic anion, Gelafusal includes the electrolytes $\mathrm{Na}^{+}, \mathrm{K}^{+}, \mathrm{Ca}^{2+}$ and $\mathrm{Cl}^{-}$as does Geloplasma except for $\mathrm{Ca}^{2+}$. In contrast, Gelafundin is only 
Table 3. Effects of different volume replacement solutions on electrolyte and metabolic parameters as well as $\mathrm{pH}$ during and subsequent to normovolemic hemodilution in urine.

\begin{tabular}{|c|c|c|c|c|c|c|c|c|c|c|c|}
\hline \multirow[t]{2}{*}{ Volume } & \multirow[t]{2}{*}{$\begin{array}{l}\text { replacement } \\
\text { solution }\end{array}$} & \multirow[t]{2}{*}{ Interval } & \multirow{2}{*}{ 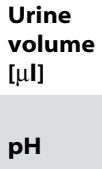 } & \multicolumn{8}{|c|}{ Parameter } \\
\hline & & & & $\begin{array}{l}\mathbf{c K}^{+} \\
{[\mathbf{m M}]}\end{array}$ & $\begin{array}{l}\mathbf{K}^{+} \\
\text {[umol] }\end{array}$ & $\begin{array}{l}\mathrm{CNa}^{+} \\
{[\mathrm{mM}]}\end{array}$ & $\begin{array}{l}\mathrm{Na}^{+} \\
{[\mu \mathrm{mol}]}\end{array}$ & $\begin{array}{l}\mathrm{CCl}^{-} \\
{[\mathrm{mM}]}\end{array}$ & $\begin{array}{l}\mathrm{Cl}^{-} \\
{[\mu \mathrm{mol}]}\end{array}$ & $\begin{array}{l}\text { cGlucose } \\
\text { [mg/dl] }\end{array}$ & $\begin{array}{l}\text { Glucose } \\
\text { [mg] }\end{array}$ \\
\hline \multirow[t]{3}{*}{ Voluven } & Initial & $217 \pm 114$ & $7.2 \pm 0.2$ & $62.9 \pm 3.1$ & - & $54.0 \pm 1.7$ & - & $49.0 \pm 4.1$ & - & $18.0 \pm 2.0$ & - \\
\hline & Dilution & $5267 \pm 666$ & $6.2 \pm 0.1$ & $125.3 \pm 5.1$ & $612.6 \pm 0.0$ & $103.0 \pm 2.5$ & $553.4 \pm 0.2$ & $182.0 \pm 6.4$ & $906.1 \pm 0.1$ & $425.0 \pm 80.5$ & $9.5 \pm 4.0$ \\
\hline & $\begin{array}{l}\text { Observation } \\
\text { time }\end{array}$ & $3433 \pm 593$ & $6.1 \pm 0.1$ & $132.2 \pm 5.8$ & $458.91 \pm 0.1$ & $104.5 \pm 5.7$ & $408.1 \pm 0.1$ & $205.0 \pm 11.2$ & $780.8 \pm 0.2$ & $321.5 \pm 43.6$ & $9.0 \pm 3.7$ \\
\hline \multirow[t]{3}{*}{ Volulyte } & Initial & $630 \pm 99$ & $7.6 \pm 0.1$ & $64.0 \pm 5.2$ & - & $71.5 \pm 4.8$ & - & $65.0 \pm 9.3$ & - & $8.4 \pm 0.4$ & - \\
\hline & Dilution & $2540 \pm 244$ & $6.4 \pm 0.2$ & $98.4 \pm 3.8$ & $265.8 \pm 0.0$ & $62.0 \pm 2.8$ & $175.9 \pm 0.0$ & $90.5 \pm 4.9$ & $260.3 \pm 0.1$ & $453.0 \pm 71.4$ & $12.7 \pm 6.8$ \\
\hline & $\begin{array}{l}\text { Observation } \\
\text { time }\end{array}$ & $2580 \pm 480$ & $6.5 \pm 0.2$ & $130.8 \pm 5.1$ & $353.1 \pm 0.1$ & $67.5 \pm 3.1$ & $201.2 \pm 0.1$ & $136.5 \pm 8.8$ & $384.4 \pm 0.1$ & $435.6 \pm 91.3$ & $14.7 \pm 10.2$ \\
\hline \multirow[t]{3}{*}{ Gelafundin } & Initial & $600 \pm 183$ & $7.2 \pm 0.2$ & $92.8 \pm 3.4$ & - & $71.5 \pm 2.5$ & - & $85.0 \pm 5.4$ & - & $15.0 \pm 0.8$ & - \\
\hline & Dilution & $2242 \pm 114$ & $6.1 \pm 0.1$ & $168.3 \pm 4.6$ & $378.9 \pm 0.0$ & $50.0 \pm 1.3$ & $113.5 \pm 0.0$ & $81.5 \pm 5.1$ & $183.7 \pm 0.0$ & $40.0 \pm 1.0$ & $0.9 \pm 0.1$ \\
\hline & $\begin{array}{l}\text { Observation } \\
\text { time }\end{array}$ & $1867 \pm 182$ & $6.1 \pm 0.1$ & $206.7 \pm 3.1$ & $381.9 \pm 0.0$ & $64.5 \pm 2.2$ & $123.0 \pm 0.0$ & $226.0 \pm 7.6$ & $412.3 \pm 0.0$ & $58.0 \pm 4.4$ & $1.0 \pm 0.2$ \\
\hline
\end{tabular}

Note: Calculations were made based on the values of the six individual animals. Therefore calculations using mean values may differ. doi:10.1371/journal.pone.0072848.t003

composed of $\mathrm{Na}^{+}$and $\mathrm{Cl}^{-}$apart from succinylated gelatin. For those two solutions containing HES as colloid osmotic substance, there are also differences in the composition of the crystalloid carrier solution. Voluven only contains $\mathrm{Na}^{+}$and $\mathrm{Cl}^{-}$as electrolytes and is therefore the counterpart to Gelafundin. Volulyte includes apart from these two ions $\mathrm{K}^{+}, \mathrm{Mg}^{2+}$ as well as acetate $(34 \mathrm{mM})$.

Expectedly, animals treated with solutions containing a metabolizable anion (i.e., Gelafusal, Geloplasma or Volulyte) experienced normalization of $\mathrm{pH}$ in terms of a slight alkalization. Unexpectedly, so did animals that had been diluted by using Gelafundin or Voluven, which do not include any metabolizable anion. Despite the fact, that Gelafusal, Geloplasma and Volulyte contain $\mathrm{K}^{+}$, in contrast to Gelafundin and Voluven, plasma $\mathrm{K}^{+}$ concentration declined continuously in all groups examined. On the other hand, the plasma $\mathrm{Cl}^{-}$concentration increased continuously independent of the solution used for dilution, even though two of the solutions (Gelafusal and Geloplasma) displayed subphysiological $\mathrm{Cl}^{-}$concentrations. Irrespective of the marked differences in their compositions, however, all of the volume replacement solutions tested (Gelafundin, Gelafusal, Geloplasma, Voluven and Volulyte) turned out to be suitable for severe normovolemic hemodilution.
Conditioned by a light initial respiratory depression due to anesthesia with isoflurane $[27,28]$, a mild respiratory acidosis existed at the beginning of the experiments in all animals studied (Figure 4) which, however, normalized until the end of hemodilution (decrease in $\mathrm{pCO}_{2}$ to values around $40 \mathrm{mmHg}$, Figure 4). In those animals substituted with either Gelafusal, Geloplasma or Volulyte there was not any indication for a metabolic disturbance of the acid-base status during and following hemodilution (base excess around $\pm 2 \mathrm{mM}$, Figure 4 ). This behaviour is clearly in line with the concept of metabolizable anions stabilizing plasma $\mathrm{pH}$ due to bicarbonate production during their degradation, thereby antagonizing a suspected dilutional acidosis [11]. On the other hand, according to the concept of dilutional acidosis, one should expect a drastic decrease in $\mathrm{HCO}_{3}{ }^{-}$and thus a decrease in base excess and $\mathrm{pH}$ upon dilution with Gelafundin or Voluven which lack any metabolizable anion [11,29]. This, however, did not occur (Figure 4). Instead, the base excess and the $\mathrm{pH}$ were slightly decreased in those groups but still remained close to the values of the groups mentioned above (Gelafusal, Geloplasma and Volulyte). Only the Voluven group displayed a more distinct decline of the base excess with a value of approximately- $7 \mathrm{mM}$ at maximum in the observation time. At the end of the observation time, however, comparable values of $\mathrm{pH}$ and base excess were obtained in all groups studied. Thus, independent of the solution used for

Table 4. Quantification of succinylated gelatin in urine samples taken during and subsequent to normovolemic hemodilution.

\begin{tabular}{|c|c|c|c|c|}
\hline Sample & $\begin{array}{l}\text { Urine } \\
\text { volume }[\mu \mathrm{I}]\end{array}$ & $\begin{array}{l}\text { Concentration of } \\
\text { succinylated gelatin }[\mathrm{mg} / \mathrm{ml}]\end{array}$ & $\begin{array}{l}\text { Quantification of } \\
\text { succinylated gelatin [mg] }\end{array}$ & $\begin{array}{l}\text { Percentage of } \\
\text { amount excreted [\%] }\end{array}$ \\
\hline Initial urine Gelafundin & $600 \pm 183$ & $4.3 \pm 0.7$ & $3.9 \pm 0.5$ & - \\
\hline Dilution Gelafundin & $2242 \pm 114$ & $134.3 \pm 12.9$ & $301.8 \pm 29.6$ & 56 \\
\hline Observation time Gelafundin & $1867 \pm 182$ & $88.6 \pm 5.5$ & $165.3 \pm 16.1$ & 31 \\
\hline Observation time Voluven & $3433 \pm 593$ & $0.9 \pm 0.5$ & $1.5 \pm 0.1$ & - \\
\hline
\end{tabular}

Note: Calculations were made based on the values of the six individual animals. Therefore calculations using mean values may differ.

Calculations concerning the percental excretion were made assuming that the animal had received 540 mg succinylated gelatin during the phase of dilution.

doi:10.1371/journal.pone.0072848.t004 
hemodilution, the major alterations in the acid-base status were due to the resolution of the initial respiratory acidosis. There was only a slight metabolic acidosis occuring especially in the observation phase and which appears to be compensated by a moderate respiratory alkalosis in the end.

A plausible explanation for this unexpected outcome can be derived from alterations in the electrolyte concentrations both in plasma and in urine. Independent of the solutions used for hemodilution and thus independent of the $\mathrm{Na}^{+}, \mathrm{K}^{+}$and $\mathrm{Cl}^{-}$ concentration, plasma $\mathrm{Na}^{+}$and $\mathrm{Cl}^{-}$concentrations increased, plasma $\mathrm{K}^{+}$concentration decreased and the amount of $\mathrm{K}^{+}$ excreted into urine increased. These alterations together with the more acidic urinary $\mathrm{pH}$ strongly suggest an aldosterone-dependent mechanism, i.e., increased reabsorption of $\mathrm{Na}^{+}$and $\mathrm{Cl}^{-}$and decreased reabsorption of $\mathrm{K}^{+}$and $\mathrm{H}^{+}$in the kidneys. Release of aldosterone can occur within $20 \mathrm{~min}$ [30] and may result from intravascular volume depletion, sensed by the renin-angiotensinsystem. Loss of intravascular volume is most likely the consequence of the excretion of the respective colloid osmotic substance (succinylated gelatin or HES) into the urine, resulting in a) an enhancement of diuresis and b) a shift of water from the extracellular into the intracellular compartment. For both colloids a rather short half life has been described (in man: succinylated gelatin: approximately 150 min [1,31]; HES: 180 min [32]). Due to the small average molecular weight of succinylated gelatin of $30 \mathrm{kDa}$, these molecules can readily pass the renal barrier. The rapid elimination of about $60 \%$ of the total amount of succinylated gelatin infused in the phase of dilution and $30 \%$ in the subsequent observation time is in line with these behaviour (Table 4). HES has an initial molecular weight of $130 \mathrm{kDa}$ and thus should not pass the renal barrier immediatly. However, rats have a high activity of endogenous $\alpha$-amylase, thus soon generating fragments of HES molecules [33]. The excretion of either colloid osmotic substance should lead to enhanced diuresis. Furthermore, in both HES groups (Voluven and Volulyte), a relatively large amount of glucose was excreted (10 mg per group and interval, see below), which may further increase diuresis and additionally contributed to an enhanced urine volume. Loss of succinylated gelatin and HES in the urine should result in a reduced colloid osmotic pressure in the vascular system. This should lead to water influx into cells and thus further enhance intravascular volume depletion. The slight decrease in MAP observed in each group independent of the solution employed may be in line with such a mechanism.

While most alterations in the electrolyte concentrations in plasma or in the electrolyte amounts excreted into urine are strongly suggestive for an aldosterone-dependent response, an increased $\mathrm{Cl}^{-}$(all groups) and a constant (Volulyte and Gelafundin) or even increased $\mathrm{Na}^{+}$excretion (Voluven) appears not to be compatible with such a mechanism. However, these variations are presumably attributed to the carrier solution's composition with supraphysiological concentrations of both $\mathrm{Cl}^{-}$ Voluven $154 \mathrm{mM}$, Volulyte $110 \mathrm{mM}$, Gelafundin $120 \mathrm{mM}$, Table 1) and $\mathrm{Na}^{+}$(Voluven and Gelafundin $154 \mathrm{mM}$, Volulyte $137 \mathrm{mM}$, Table 1) and especially to the hypertonicity of Voluven (304 mOsm/ $\mathrm{kg}$; for comparison: physiological osmolality in Wistar rats $290 \mathrm{mOsm} / \mathrm{kg}$ [34], Volulyte $283 \mathrm{mOsm} / \mathrm{kg}$ and Gelafundin $265 \mathrm{mOsm} / \mathrm{kg}$, Table 1). The hypertonicity of Voluven should also account for the increased urine volume in this group (Table 3).

Other mechanisms for normalization of plasma $\mathrm{pH}$ are rather unlikely. For instance, one could assume an increased activation of the renal $\mathrm{H}^{+} / \mathrm{K}^{+}$antiporter due to dilution with a $\mathrm{K}^{+}$-free solution (Gelafundin and Voluven) and thus a decreasing plasma $\mathrm{K}^{+}$ concentration. However, plasma $\mathrm{K}^{+}$concentration also declined at a comparable rate in all other groups (Gelafusal, Geloplasma and Volulyte), although these solutions contain $\mathrm{K}^{+}$in an almost physiological range. Additionally, due to the postulated enhanced $\mathrm{K}^{+}$reabsorption via the $\mathrm{H}^{+} / \mathrm{K}^{+}$antiporter, the amount of $\mathrm{K}^{+}$ excreted should have been decreased. This was not the case. Instead, the urinary amount of $\mathrm{K}^{+}$increased both during the phase of dilution and during the observation time in all experimental groups studied (Table 3).

In the HES groups, but also in the Gelafundin group, vacuolization of proximal tubular cells was observed, a histopathologically finding generally known as osmotic nephrosis. According to the classification of Janssen et al., this alteration only corresponds to a slight damage [35], whose presence does not necessarily impair renal function [36]. Actually, the observed responses in electrolyte and acid-base homeostasis strongly support this assumption. Osmotic nephrosis due to treatment with HES has already been shown in the past [37-39]. The present results suggest that such an injury may also result from application of succinylated gelatin, in line with few existing reports about adverse renal effects elicited by solutions containing gelatin [40].

The elevated excretion of glucose in both HES groups is in line with previous findings obtained in a model of an isolated perfused pig kidney model [37]. Since renal damage is unlikely to account for this observation, competitive inhibition of glucose re-uptake by the HES molecules may be responsible for the impaired renal uptake of glucose. In support of such a mechanism, only minor amounts of glucose were found in the urine of the Gelafundin group.

The slight increase in $\mathrm{Ca}^{2+}$ concentration shortly before cessation of dilution and the subsequent decline to the initial level in the groups containing succinylated gelatin cannot be explained by the composition of the respective carrier solution (Table 1). The alterations, however, were only small and no differences were observed between the Gelafusal group, which contains $\mathrm{Ca}^{2+}$, and both other groups lacking this cation (Gelafundin and Geloplasma).

As can be seen from the reliable achievement of the critical hematocrit in any group, there were no differences in the quality of dilution between the solutions employed (Figure 2 for those animals having been diluted with succinylated gelatin). In all groups, all animals survived the experiment, although they experienced maximal hemodilution (until the critical hematocrit). We have no explanations for the observed sudden changes in $\mathrm{Ca}^{2+}$ concentration, base excess and $\mathrm{pCO}_{2}$ after cessation of dilution but they may be related to the achievment of the critical hematocrit. Furthermore, in the groups diluted without exogenous lactate (all except Geloplasma), the plasma lactate concentration remained below $1.9 \mathrm{mM}$ until the end of the experiment (Table 2). This indicates that the animals did not suffer from overt ischemia despite of the severe hemodilution applied. There was no evidence for any impairment due to an increased oxygen demand as suggested for the administration of lactate [41] or for short-term drops in blood pressure due to vasodilatating effects as proposed for acetate $[11,42]$.

In our study we decided not to use a hemorrhagic shock model, but a model of severe normovolemic hemodilution. Our goal was to study the influence of the crystalloid carrier solution on acidbase status rather than the effect of the colloid used for fluid replacement on hemodynamics. The model of normovolemic hemodilution to a final hematocrit of $10 \%$ provides the opportunity of infusing a maximal amount of volume replacement solution possible. In addition, the obtained results are not subjected to acid-base disturbances like metabolic acidosis as would be expected in a hemorrhagic shock model. On the other 
hand, due to the removal of large amounts of proteins and other osmotically active substances in the course of normovolemic hemodilution another limitation is the need to employ a colloidbased volume replacement solution instead of an only crystalloidbased solution to maintain intravascular oncotic pressure.

The current findings clearly indicate that metabolizable anions such as lactate or acetate as well as $\mathrm{Ca}^{2+}$ and $\mathrm{K}^{+}$being present in the carrier solution do not bring further improvement even during severe normovolemic hemodilution. Thus, with regard to the composition of the carrier solution, there seem to be only minimal requirements, which are isoosmolarity on the one hand and the

\section{References}

1. Mitra S, Khandelwal P (2009) Are all colloids same? How to select the right colloid? Indian J Anaesth 53: 592-607.

2. Perel P, Roberts I (2012) Colloids versus crystalloids for fluid resuscitation in critically ill patients. Cochrane Database Syst Rev 6: CD000567.

3. Choi PT, Yip G, Quinonez LG, Cook DJ (1999) Crystalloids vs. colloids in fluid resuscitation: a systematic review. Crit Care Med 27: 200-210.

4. Levi M, Jonge E (2007) Clinical relevance of the effects of plasma expanders on coagulation. Semin Thromb Hemost 33: 810-815.

5. Nolan J (1999) Fluid replacement. Br Med Bull 55: 821-843.

6. Mizzi A, Tran T, Karlnoski R, Anderson A, Mangar D, et al. (2011) Voluven, a new colloid solution. Anesthesiol Clin 29: 547-555.

7. Forster H (1997) [Hydroxyethyl starch as a plasma substitute]. Krankenpfl J 35: 497-506.

8. Westphal M, James MF, Kozek-Langenecker S, Stocker R, Guidet B, et al. (2009) Hydroxyethyl starches: different products-different effects. Anesthesiology 111: 187-202.

9. Wiedermann CJ (2004) Hydroxyethyl starch-can the safety problems be ignored? Wien Klin Wochenschr 116: 583-594.

10. Rehm M, Orth V, Scheingraber S, Kreimeier U, Brechtelsbauer H, et al. (2000) Acid-base changes caused by $5 \%$ albumin versus $6 \%$ hydroxyethyl starch solution in patients undergoing acute normovolemic hemodilution: a randomized prospective study. Anesthesiology 93: 1174-1183.

11. Zander R (2009) Fluid Management-Second expanded edition. Melsungen: Bibliomed-Medizinische Verlagsgesellschaft mbH. 15-31 p.

12. Mortelmans YJ, Vermaut G, Verbruggen AM, Arnout JM, Vermylen J, et al. (1995) Effects of $6 \%$ hydroxyethyl starch and 3\% modified fluid gelatin on intravascular volume and coagulation during intraoperative hemodilution. Anesth Analg 81: 1235-1242.

13. Freyburger G, Dubreuil M, Boisseau MR, Janvier G (1996) Rheological properties of commonly used plasma substitutes during preoperative normovolaemic acute haemodilution. Br J Anaesth 76: 519-525.

14. Casutt M, Kristoffy A, Schuepfer G, Spahn DR, Konrad G (2010) Effects on coagulation of balanced (130/0.42) and non-balanced (130/0.4) hydroxyethyl starch or gelatin compared with balanced Ringer's solution: an in vitro study using two different viscoelastic coagulation tests ROTEMTM and SONOCLOTTM. Br J Anaesth 105: 273-281.

15. Godier A, Durand M, Smadja D, Jeandel T, Emmerich J, et al. (2010) Maize- or potato-derived hydroxyethyl starches: is there any thromboelastometric difference? Acta Anaesthesiol Scand 54: 1241-1247.

16. Lobo DN, Stanga Z, Aloysius MM, Wicks C, Nunes QM, et al. (2010) Effect of volume loading with 1 liter intravenous infusions of $0.9 \%$ saline, $4 \%$ succinylated gelatine (Gelofusine) and 6\% hydroxyethyl starch (Voluven) on blood volume and endocrine responses: a randomized, three-way crossover study in healthy volunteers. Crit Care Med 38: 464-470.

17. Margarido CB, Margarido NF, Otsuki DA, Fantoni DT, Marumo CK, et al. (2007) Pulmonary function is better preserved in pigs when acute normovolemic hemodilution is achieved with hydroxyethyl starch versus lactated Ringer's solution. Shock 27: 390-396.

18. Haas T, Fries D, Holz C, Innerhofer P, Streif W, et al. (2008) Less impairment of hemostasis and reduced blood loss in pigs after resuscitation from hemorrhagic shock using the small-volume concept with hypertonic saline/hydroxyethyl starch as compared to administration of $4 \%$ gelatin or $6 \%$ hydroxyethyl starch solution. Anesth Analg 106: 1078-1086.

19. Dubniks M, Persson J, Grande PO (2007) Plasma volume expansion of 5\% albumin, 4\% gelatin, 6\% HES 130/0.4, and normal saline under increased microvascular permeability in the rat. Intensive Care Med 33: 293-299.

20. Base EM, Standl T, Lassnigg A, Skhirtladze K, Jungheinrich C, et al. (2011) Efficacy and safety of hydroxyethyl starch $6 \% 130 / 0.4$ in a balanced electrolyte solution (Volulyte) during cardiac surgery. J Cardiothorac Vasc Anesth 25: 407414. presence of $\mathrm{Na}^{+}$together with $\mathrm{Cl}^{-}$on the other hand. This conclusion, however, is only valid if succinylated gelatin or HES is used as colloid osmotic substance.

\section{Author Contributions}

Conceived and designed the experiments: KBF HdG. Performed the experiments: JKT CM. Analyzed the data: JKT HdG CM. Contributed reagents/materials/analysis tools: CM. Wrote the paper: JKT KBF HdG. Complementation of the experimental model: FP.

21. Lehmann L, Bendel S, Uehlinger DE, Takala J, Schafer M, et al. (2012) Randomized, double-blind trial of the effect of fluid composition on electrolyte, Acid-base, and fluid homeostasis in patients early after subarachnoid hemorrhage. Neurocrit Care 18: 5-12.

22. Aksu U, Bezemer R, Demirci C, Ince C (2012) Acute effects of balanced versus unbalanced colloid resuscitation on renal macrocirculatory and microcirculatory perfusion during endotoxemic shock. Shock 37: 205-209.

23. Almac E, Aksu U, Bezemer R, Jong W, Kandil A, et al. (2012) The acute effects of acetate-balanced colloid and crystalloid resuscitation on renal oxygenation in a rat model of hemorrhagic shock. Resuscitation 83: 1166-1172.

24. Council EPaE (2010) European Commission (2010) Directive 2010/63/EU on the protection of animals used for scientific purposes.

25. Johannes T, Mik EG, Nohe B, Unertl KE, Ince C (2007) Acute decrease in renal microvascular PO2 during acute normovolemic hemodilution. Am J Physiol Renal Physiol 292: F796-803.

26. Yang ZJ, Price CD, Bosco G, Tucci M, El-Badri NS, et al. (2008) The effect of isovolemic hemodilution with oxycyte, a perfluorocarbon emulsion, on cerebral blood flow in rats. PLoS One 3: e2010.

27. Dardai E, Heavner JE (1987) Respiratory and cardiovascular effects of halothane, isoflurane and enflurane delivered via a Jackson-Rees breathing system in temperature controlled and uncontrolled rats. Methods Find Exp Clin Pharmacol 9: 717-720.

28. Imai A, Steffey EP, Farver TB, Ilkiw JE (1999) Assessment of isoflurane-induced anesthesia in ferrets and rats. Am J Vet Res 60: 1577-1583.

29. Zander R (2006) Infusion fluids: why should they be balanced solutions? EJHP Practice 12: 60-62.

30. Oberleithner H, Weigt M, Westphale HJ, Wang W (1987) Aldosterone activates $\mathrm{Na}+\mathrm{H}+$ exchange and raises cytoplasmic $\mathrm{pH}$ in target cells of the amphibian kidney. Proc Natl Acad Sci U S A 84: 1464-1468.

31. Edwards JD, Nightingale P, Wilkins RG, Faragher EB (1989) Hemodynamic and oxygen transport response to modified fluid gelatin in critically ill patients. Crit Care Med 17: 996-998.

32. Sirtl C, Laubenthal H, Schimetta W (2008) Volumenersatzlösungen. In: Roissant R, Werner C, Zwißler B, editors. Die Anästhesiologie. Heidelberg: Springer. 384-408.

33. Förster HA F (1998) Grundlagen der Anwendung von Hydroxyethylstärke-Was ist gesichert, was ist Spekulation? J A I 5: 2-11.

34. Morris M (1982) Neurohypophyseal response to dehydration in the spontaneously hypertensive rat. Hypertension 4: 161-166.

35. Janssen CW Jr (1968) Osmotic nephrosis. A clinical and experimental investigation. Acta Chir Scand 134: 481-487.

36. Dickenmann M, Oettl T, Mihatsch MJ (2008) Osmotic nephrosis: acute kidney injury with accumulation of proximal tubular lysosomes due to administration of exogenous solutes. Am J Kidney Dis 51: 491-503.

37. Hauet T, Faure JP, Baumert H, Bardou A, Gibelin H, et al. (1998) Influence of different colloids on hemodynamic and renal functions: comparative study in an isolated perfused pig kidney model. Transplant Proc 30: 2796-2797.

38. Legendre C, Thervet E, Page B, Percheron A, Noel LH, et al. (1993) Hydroxyethylstarch and osmotic-nephrosis-like lesions in kidney transplantation. Lancet 342: 248-249.

39. Winkelmayer WC, Glynn RJ, Levin R, Avorn J (2003) Hydroxyethyl starch and change in renal function in patients undergoing coronary artery bypass graft surgery. Kidney Int 64: 1046-1049.

40. Kief H, Engelbart K, Arnold G, Bahr H (1968) [Vacuolar reabsorption of native and digested gelatin (so-called osmotic nephrosis)]. Virchows Arch B Cell Pathol 1: $240-250$.

41. Alpert NR, Root WS (1954) Relationship between excess respiratory metabolism and utilization of intravenously infused sodium racemic lactate and sodium L(-) lactate. Am J Physiol 177: 455-462.

42. Frohlich ED (1965) Vascular Effects of the Krebs Intermediate Metabolites. Am J Physiol 208: 149-153. 